Casos Clínicos

Arch. Esp. Urol., 61, 6 (730-733), 2008

\section{TRATAMIENTO QUIRÚRGICO DE CARCINOMA RENAL CON TROMBO Y FILTRO EN VENA CAVA}

Joaquín Ulises Juan Escudero, Macarena Ramos de Campos, Sergio Cánovas López', Milagros Fabuel Deltoro y Emilio Marqués Vidal.

Servicio de Urología y Servicio de Cirugía Cardiaca. Consorcio Hospital General Universitario de Valencia. Valencia. España.

Resumen.- OBJETIVO: La invasión vascular en forma de trombo tumoral sucede en un no desdeñable porcentaje de las neoplasias renales, la importancia de la extensión cefálica del trombo en el pronóstico es discutida actualmente pero en ausencia de metástasis a distancia, el tratamiento quirúrgico es mandatorio.

MÉTODO: Presentamos el caso de un paciente de 56 años al que intervenimos en nuestro centro, portador de filtro en vena cava inferior mediante abordaje toraco-abdominal con circulación extracorpórea (CEC), hipotermia profunda (por debajo de los $18^{\circ} \mathrm{C}$ ) y retroperfusión cerebral.
RESULTADOS: Si bien tiempo atrás se pensaba que la presencia de trombo tumoral ensombrecía el pronóstico de estos pacientes, actualmente sabemos que con tratamiento quirúrgico, en casos seleccionados, se obtienen buenos resultados en términos de supervivencia y tiempo libre de enfermedad.

CONCLUSIÓN: Pensamos que el implante de filtros venosos, puede incrementar la complejidad de la cirugía.

Palabras clave: Cancer renal. Extensión vascular. Filtro venoso.

Summary.- OBJECTIVE: Vascular invasion in the form of tumour thrombus appears in a significant percentage of renal neoplasias. The importance of cephalic extension of the thrombus in prognosis is currently under discussion, but surgical treatment is mandatory in the absence of distant metastasis.

METHODS: We report the case of a 56-year-old male patient with a filter in the inferior vena cava, who underwent surgery in our department through a thoracoabdominal approach with extracorporeal circulation, deep hypothermia (below $18^{\circ} \mathrm{C}$ ) and cerebral retrograde perfusion.

RESULTS: Although in the past it was believed tumour thrombus worsened prognosis in these patients, currently we know that surgical treatment, in selected cases, gives good results in terms of survival and disease-free time.

CONCLUSIONS: We think the implementation of venous filters may increase the complexity of surgery.

Keywords: Renal cancer. Vascular extension. Venous filter.

\section{INTRODUCCIÓN}

A pesar de una reducción notable en su incidencia gracias al uso extendido de las técnicas de imagen como la ecografía, la invasión vascular por trombo tumoral en las neoplasias renales supone un $10 \%$ de los casos. Si bien actualmente, es conocido que la cirugía consigue tasas de supervivencia y periodos libres de enfermedad que se acercan a los casos sin invasión vascular.

El uso de filtros venosos para evitar la progresión del trombo y la embolización a distancia se encuentra bastante extendido, si bien podría suponer una ventaja en materia de reducción de la diseminación pulmonar del trombo tumoral en estos pacientes puede ser responsable de incrementar la complejidad de la cirugía. 
Presentamos nuestra experiencia quirúrgica en un paciente con trombo en vena cava inferior tipo 2 portador de paraguas de cava intervenido en nuestro centro.

\section{CASO CLÍNICO}

Paciente de 56 años remitido a nuestro servicio por hallazgo incidental de masa renal de $5 \mathrm{~cm}$ de diámetro máximo, mesorrenal izquierda en la ecografía durante el estudio de cuadro de crisis renoureteral del mismo lado. Como único antecedente el paciente padece hiperuricemia, y no refiere haber presentado episodios de hematuria. En el centro donde se diagnosticó se realizó estudio de extensión con radiografía de tórax, hemograma, bioquímica y tomografía computerizada abdomino-pélvica, donde se evidenció trombo tumoral que se extendía por la vena renal hasta la vena cava retrohepática. Ante este caso se decidió en el centro emisor, colocar filtro en vena cava inferior para evitar la progresión y la embolización de dicho trombo. Posteriormente el paciente fue remitido a nuestro centro para valorar tratamiento quirúrgico, ya que el centro emisor carecía de servicio de cirugía cardiaca.

Para completar estudio realizamos urografías por resonancia magnética (Uro-RNM), y estudio angiográfico mediante tomografía computerizada (angio-TC) (Figura 1) con cavografía para valorar con la máxima precisión posible el alcance del trombo y la posible infiltración vascular tumoral. En ambas exploraciones se informa de la extensión retrohepática del trombo, la aparente

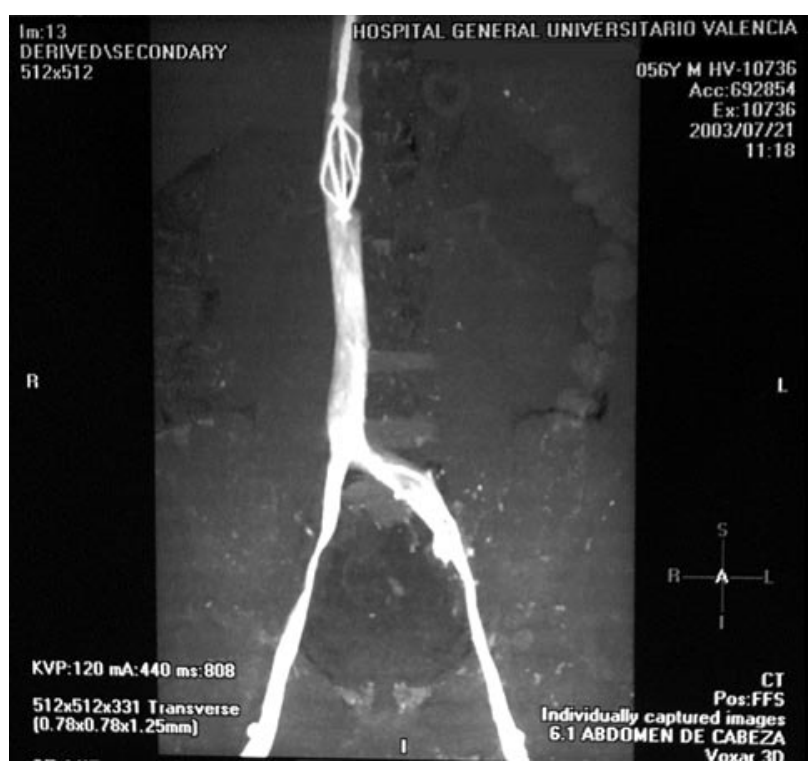

FIGURA 1. Imagen del TC cavografia en el que se ve el filtro de vena cava. ausencia de infiltración vascular y de adenopatías, así como la presencia de filtro metálico inmediatamente por encima del trombo, responsable de la artefactación de las imágenes.

Con el diagnóstico de neoformación renal estadio T3bNOMO con trombo tumoral nivel II, se decide intervenir, conjuntamente con el servicio de cirugía cardiaca de nuestro centro, realizando esternotomía y laparotomía subcostal izquierda y, previa liberación del ángulo esplénico del colon mediante apertura del retroperitoneo a nivel del mesenterio, nefrectomía radical izquierda permaneciendo la pieza de nefrectomía anclada por la vena renal trombosada. Posteriormente, y bajo circulación extracorpórea con hipotermia profunda y retroperfusión cerebral, se procede a la retirada del filtro (Figura 2) por cierre del mismo y tracción bajo control fluoroscópico desde su punto de inserción a nivel yugular, con control por auriculotomía derecha de la posible diseminación a pulmón de pequeños trombos durante la maniobra de retirada, para realizar acto seguido la resección de la vena renal y su ostium por sospecha de infiltración de los mismos y trombectomía (Figura 3) por tracción para reparar posteriormente el defecto con un parche de Gore-tex $\AA^{\circledR}$, precisando por este motivo el paciente anticoagulación con dicumarínicos durante 3 meses, hasta la endotelización del injerto sintético.

La anatomía patológica revela la existencia de adenocarcinoma renal, grado III de Furhman que infiltra la cápsula renal sin sobrepasarla así como la vena renal, no encontrándose infiltrada la vena cava (pT3bNoMo) con trombo de origen exclusivamente tumoral.

El paciente sigue en revisiones en nuestras consultas hasta que, en el TC de control a los 12 meses se evidencia

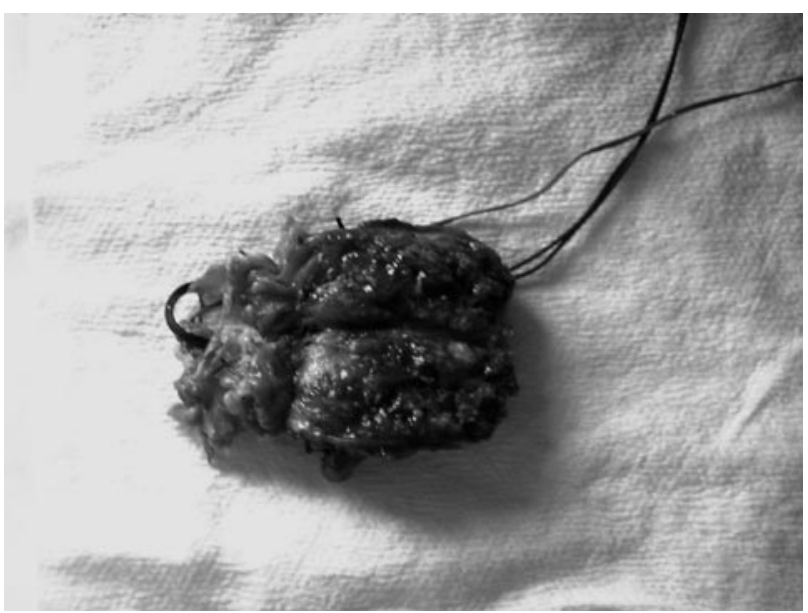

FIGURA 2. Trombo tumoral. 


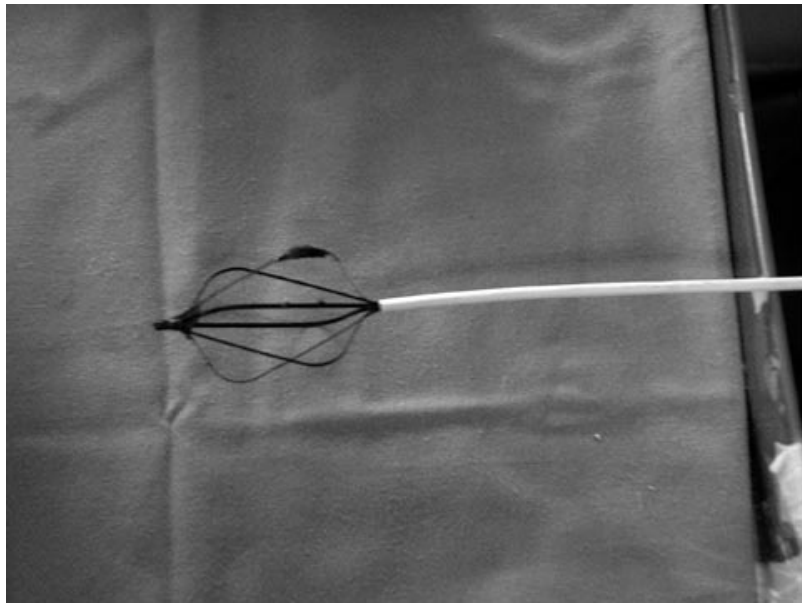

FIGURA 3. Imagen del filtro de vena cava.

lesión lítica en lámina posterior de la vértebra $L 2$, tras estudio de extensión con gammagrafía y TC total-body que confirman que se trata de una lesión única, es remitido al servicio de neurocirugía donde es intervenido realizándose resección de dicha lesión. Actualmente, han transcurrido 20 meses de seguimiento tras la nefretomía, el paciente se encuentra en revisiones por nuestro servicio y el servicio de oncología médica, encontrándose asintomático y sin signos de recidiva.

\section{DISCUSIÓN}

El carcinoma de células renales supone un 3\% del total de neoplasias en el adulto. Su presentación con trombo venoso, aunque ha reducido su incidencia gracias a el uso extendido de la ecografía, se cifra en aproximadamente el $10 \%(1)$.

Durante años la influencia de la presencia de trombo tumoral en el pronóstico de la enfermedad ha sido fuente de discusión, si bien hoy en día, gracias a diferentes estudios parece demostrado que, si no existen metástasis ni afectación ganglionar, el tratamiento quirúrgico de esta enfermedad consigue tasas libres de enfermedad y de supervivencia similares a los casos sin trombo vascular (1-4).

A pesar de encontrarse actualmente en debate la influencia del alcance del trombo tumoral en el pronóstico, y en consecuencia, en la clasificación (5), sigue vigente la clasificación TNM de 2002, en la que se diferencia entre la extensión del trombo en supra e infradiafragmática, aunque parece lógico, teniendo en cuenta la estrategia quirúrgica que vamos a seguir, dividir la extensión cefálica del trombo subdiafragmática en: suprahepática, retrohepática e infrahepática. En el caso de extensión retro y suprahepáticas, así como supradiafragmáticas, hemos de considerar el empleo de CEC debido a la reducción de la pérdida hemática cuando se utiliza esta técnica En este sentido, también podemos diferenciar del resto la presencia de trombo dentro de la aurícula derecha en vistas de planificar la cirugía.

En cuanto al diagnóstico la RNM es la prueba más sensible y específica para la valoración de la presencia y extensión del trombo en los vasos (6), siendo de gran utilidad, como complementario a esta la ecocardiografia transesofágica, sobretodo en estadios T3c. Del mismo modo resulta más sensible para realizar el diagnostico diferencial entre la trombosis aislada o la infiltración vascular directa tumoral, si bien en nuestra experiencia encontramos muy útil el angio-TC para valorar la existencia de vascularización accesoria. En nuestro caso, si bien artefacto las imágenes de diagnóstico radiológico, el material del filtro (nitinol) no supuso una contraindicación a la realización de la resonancia magnética.

Para trombos de nivel II, como en nuestro caso, la mayoría de autores realiza un abordaje abdominal con laparotomía subcostal y movilización hepática, pero nosotros preferimos realizar la extracción del filtro con total seguridad para lo que creímos necesario realizarla desde la aurícula por lo que la esternotomía resultó imperativa.

El uso de filtros venosos para evitar la siembra tumoral y la embolización pulmonar, defendido por muchos autores $(2,7)$ es controvertido, si bien parece razonable evitar dichas complicaciones y para ello esto resulta un gesto quirúrgico sencillo y mínimamente invasivo, pero ,como ha sucedido en nuestro caso, puede dificultar enormemente la cirugía a la hora de su extracción, en la que tuvimos que acceder a la aurícula derecha para hacerlo bajo control visual con garantías de seguridad, si no se hubiese colocado, posiblemente hubiéramos ahorrado el gesto de apertura de la aurícula y por lo tanto de circulación extracorpórea con los riesgos que esto conlleva. De este modo en nuestro centro preferimos instaurar terapia antitromboembólica con heparinas de bajo peso molecular y no demorar la cirugía más allá de lo necesario para completar el estudio preoperatorio y no realizar colocación de filtros venosos provisionales, que, como sucedió en nuestro caso, al encontrárse demasiado próximo al trombo dificultó la cirugía.

Por último resaltar que la resección de metástasis solitarias, siempre y cuando sea técnicamente posible ofrece buenos resultados en términos de supervivencia y tiempo libre de enfermedad, por lo que decidimos tomar una actitud quirúrgica en nuestro paciente.

\section{CONCLUSIONES}

La nefrectomía radical con trombectomía es el tratamiento de elección del carcinoma renal con trombosis en vena renal, vena cava y aurícula derecha en ausencia de enfermedad metastásica múltiple. Consideramos es- 
pecialmente útil la realización de esta intervención con el apoyo de cirugía vascular en estadios III,IV y en casos complejos de estadios II a fin de reducir la mortalidad asociada a la gran pérdida hemática secundaria a la disección para el control de la cava inferior a nivel de los grandes vasos suprahepáticos.

El uso de paraguas provisionales de vena cava puede ser muy útil para evitar la embolización pulmonar, sobre todo en casos de que éste trombo sea tumoral donde evitaremos además la diseminación tumoral. En nuestra opinión, siempre que sea posible preferimos evitar su uso y demorar lo mínimo posible la cirugía.

\section{BIBLIOGRAFÍA Y LECTURAS RECOMENDADAS (*lectura de interés $y$ ** lectura fundamental)}

*1. BOORJIAN, S.A.; SENGUPTA, S.; BLUTE, M.L.: "Renal cell carcinoma: Vena caval involvement". BJU Int, 99: 1239, 2007.

2. GARCIA, O.D.; FERNANDEZ, F.E.; HONRUBIA, A. y cols.: "Surgical stratification of renal carcinoma with extension into inferior vena cava". Actas Urol. Esp., 29: 448, 2005.

3. JIBIKI, M.; IWAI, T.; INOUE, Y. y cols.: "Surgical strategy for treating renal cell carcinoma with thrombus extending into the inferior vena cava". J. Vasc. Surg., 39: 829, 2004.

**4. LAMBERT, E.H.; PIERORAZIO, P.M.; SHABSIGH, A. y cols.: "Prognostic risk stratification and clinical outcomes in patients undergoing surgical treatment for renal cell carcinoma with vascular tumor thrombus". Urology, 69: 1054, 2007.

5. FICARRA, V.; GALFANO, A.; GUILLE, F. y cols.: “A new staging system for locally advanced (pT3-4) renal cell carcinoma: A multicenter European study including 2,000 patients". J. Urol., 178: 418, 2007.

6. LAWRENTSCHUK, N.; GANI, J.; RIORDAN, R. y cols.: "Multidetector computed tomography vs magnetic resonance imaging for defining the upper limit of tumour thrombus in renal cell carcinoma: A study and review". BJU Int., 96: 291, 2005.

7. BLUTE, M.L.; BOORJIAN, S.A.; LEIBOVICH, B.C. y cols.: "Results of inferior vena caval interruption by greenfield filter, ligation or resection during radical nephrectomy and tumor thrombectomy". J. Urol., 178: 440, 2007. 